Department of HEALTH (1991) The Health of the Nation London: HMSO.

Honig. A., POP, P.. TAN, S., et al (1989) Physical illness in chronic psychiatric patients from a community psychiatric unit. The implications for daily practice. British Journal of Psychiatry. 155. 58-64.

JENKINS, R. (1990) Towards a system of outcome indicators for mental health care. British Journal of Psychiatry. 157, 500-514.

KENDRICK. T. (1993) Care of patients with schizophrenia. British Journal of General Practice, 43, 259-260.

-. SibBald. B., BuRns. T., et al (1991) Role of general practitioners in care of long-term mentally ill patients. British Medical Journal, 302. 508-510.
PERKINS. R. (1996) Rehabilitation and Continuing Care Service Clinical Audit: 1996 Annual Report. London: Pathfinder NHS Mental Health Services Trust.

*Nigel Fisher, Consultant Psychiatrist, Rehabilitation and Continuing Care Service, Springfield Hospital, 61 Glenburnie Road, London SW17 7DJ and Judy Roberts, General Practitioner. The Surgery, 219A Upper Tooting Road, London

*Correspondence

\title{
Satisfaction of attenders and non- attenders with their treatments at psychiatric out-patient clinics
}

\author{
Helen Killaspy, Julia Gledhill and Sube Banerjee
}

\begin{abstract}
Aims and method Non-attendance at psychiatric outpatient appointments has a substantial financial cost. and may also have clinical significance. To prevent non-attendance and formulate effective responses, its determinants need to be understood. Patient dissatisfaction with services has been suggested as a reason for non-attendance. we therefore investigated the role of patient satisfaction in attendance at psychiatric out-patients appointments. All patients booked for adult psychiatric out-patient follow-up appointments in a three-month period were studied using a brief, self-report questionnaire.

Results Sixty-three per cent (340/538) of attenders and $54 \%(118 / 219)$ of non-attenders responded. Responders expressed high levels of satisfaction with their treatment (92\% attenders, 91\% non-attenders) and with the service (96\% attenders, $92 \%$ non-attenders). Despite adequate statistical power, there were no statistically significant differences in satisfaction between the two groups.

Clinical implications In conclusion, patient satisfaction with psychiatric out-patient care was reported to be relatively high and did not seem to be an important determinant of non-attendance. Further work is needed to determine the impact of variables such as relapse and social disorganisation on attendance.
\end{abstract}

Developments such as the Patient's Charter have clarified the need for services to attend to user views and satisfaction. Despite innovations in service delivery and reports that home-based services can reduce non-attendance from 25 to $7 \%$ (Burns et al, 1993a), the out-patient psychiatric consultation remains the main form of contact between patients in the community and psychiatrists, perhaps due to the greater costs and time perceived to be associated with homebased services. There has, however, been little systematic study of user views of out-patient services. High non-attendance rates at psychiatric out-patient clinics of between 20 and 57\% (Baekland \& Lundwall. 1975; Carpenter et ah 1981: Morgan, 1989) have been reported, but the reasons behind this time consuming and expensive waste of scarce resources have not been investigated.

Within general medical out-patients, fixed appointment times and seeing the same doctor on successive occasions have been rated as the most important factors in consultations (Bishop et al, 1991); also patients who rate their outpatient service poorly are likely to leave their physicians (Rubin et al, 1993). Studying psychiatric in-patients. McIntyre et al (1989) reported that patients rated the ability to leave the ward when they wished and being able to talk to staff as the most important aspects of treatment. 
In the USA, a study within community settings reported that clients were highly satisfied with community drop-in centres and that their main difficulties were with transportation and inflexible opening times (Kaufmann et al, 1993). Huxley \& Warner (1992) comparing case management models in Colorado found an improved quality of life was associated with regular monitoring, but that satisfaction with treatment was reduced by being visited too frequently. Jones \& Lodge (1991) assessed psychiatric outpatient attenders over a two-week period and concluded that satisfaction with services was related to the quality of communication within the consultation and, for new patients, the time from first referral to assessment.

No study to date has investigated the views of out-patient non-attenders. We therefore set out to evaluate satisfaction with psychiatric outpatient services and to investigate whether nonattendance was a function of dissatisfaction in order to identify potential measures to prevent non-attendance.

\section{The study}

The study was carried out in the psychiatric outpatient department of the Royal Free Hospital, London over a three-month period between October 1995 and January 1996. The psychiatric service covers a geographically defined innercity catchment area. All follow-up general adult patients due to attend the clinic in the study period were given or sent a brief, anonymised, self-report questionnaire incorporating items from instruments previously used (Jones \& Lodge, 1991; Ruggeri \& Dall'Agnola, 1993). This consisted of 20 multiple choice questions with space for patients to add their own comments. Data collected included: socio-demographic details, past psychiatric history, current outpatient use, quality of interaction with their psychiatrist, satisfaction with treatment received from their psychiatrist, and satisfaction with the out-patient service as a whole.

All attenders who agreed to participate were given a questionnaire by the reception staff who collected them on completion. Patients were defined by their first contact during the study period as an attender or a non-attender. Those with two or more appointments within the study period were only given, or sent, a questionnaire at their first appointment. Those who did not attend were sent a questionnaire and asked to return it to the department in a pre-paid envelope. If there was no response within three weeks a further copy was sent with an explanatory letter. Two tailed $t$-tests and $\chi^{2}$ tests were carried out to examine for differences between attenders and non-attenders.

\section{Findings}

During the study period, 1087 follow-up appointments were attended (538 individuals) and 416 were not ( 219 individuals), a non-attendance rate of $28 \%$. Three hundred and forty completed questionnaires were received from the attenders. giving a response rate of $63 \%$ for those who attended their appointment. One hundred and eighteen completed postal questionnaires were returned from the non-attenders, giving a response rate of $54 \%$ for those who did not attend their appointment.

Fifty of the study population were female $(51 \%$ of attenders and $48 \%$ of non-attenders); $79 \%$ classified themselves as White Europeans $(81 \%$ of attenders and $73 \%$ of non-attenders) and $9 \%$ as African-Caribbean ( $8 \%$ of attenders and $12 \%$ of non-attenders): $76 \%$ were unemployed $(76 \%$ of attenders and $78 \%$ of non-attenders); $8 \%$ lived in supported accommodation $(6 \%$ of attenders and $12 \%$ of non-attenders) and the mean age was 41 years (41 years for attenders and 40 years for non-attenders). There were no statistically significant differences in socio-demographic variables between attenders and non-attenders. Forty-one per cent of the study group usually saw a consultant and $80 \%$ said they wanted to see their consultant at least sometimes. Seventytwo per cent of consultations lasted between 10 and 30 minutes; $28 \%$ reported their consultations were not long enough. Forty-three per cent had been admitted to the ward within the past two years. Twenty-five per cent had been attending the out-patient department for over five years and $9 \%$ for less than one month.

In terms of the quality of consultation, $90 \%$ of patients felt that they were always or usually able to ask all the questions they wanted to; $93 \%$ that they always or usually received adequate answers; and $95 \%$ that they felt they understood the things their doctor explained to them. Comparing the distribution of these variables between the attenders and non-attenders there were no statistically significant differences, the results are summarised in Table 1.

High levels of satisfaction were reported by both attenders and non-attenders, with no statistically significant difference between the two groups. Over $90 \%$ of both groups stated that they were satisfled or very satisfied with both the treatment from their doctor and with the general service they received in the out-patient department (Table 1). The most common criticism of the service was that junior medical staff changed every six months leading to a sense of discontinuity of treatment for patients.

\section{Comment}

The most striking finding of this study was the lack of any difference in satisfaction and other 
Table 1. Patient satisfaction with out-patient psychiatric management

\begin{tabular}{lcc}
\hline & $\begin{array}{c}\text { Attenders, } \\
\mathbf{n}(\%)\end{array}$ & $\begin{array}{l}\text { Non-attenders } \\
\mathbf{n}(\%)\end{array}$ \\
\hline Satisfaction with out-patient treatment from doctor' \\
Very satisfied & $113(34)$ & $33(29)$ \\
Satisfied & $191(58)$ & $71(62)$ \\
Dissatisfied & $19(6)$ & $8(7)$ \\
Very dissatisfied & $6(2)$ & $3(3)$ \\
Satisfaction with the general out-patient service \\
Very satisfied & $139(42)$ & $42(36)$ \\
Satisfied & $181(54)$ & $66(56)$ \\
Dissatisfied & $9(3)$ & $6(5)$ \\
Very dissatisfied & $4(1)$ & $1(1)$ \\
\hline
\end{tabular}

1. $\chi^{2}=1.48, P=0.69$.

2. $x^{2}=2.42, P=0.49$.

variables studied between attenders and nonattenders. Interpreting negative findings can be problematic and we need to consider the possibility that an observed lack of association is a function of a lack of statistical power. In this case, this seems unlikely since the relatively large numbers recruited would have resulted in sufficient statistical power to identify a difference of $7 \%$ in levels of dissatisfaction between the two groups. Another important potential source of error is the difficulty implicit in the assessment of user satisfaction. Users may feel a need to express satisfaction to those providing the service. In this study we sought to minimise this by the use of anonymised self-report forms, but the potential for error in the measurement of satisfaction remains.

Our study suggests that dissatisfaction may not be an important determinant of non-attendance. The main potential source of bias in the interpretation of our results comes from the high non-response rate, our study confirms the limitations of using a postal technique in the investigation of psychiatric non-attenders suggested by studies of other out-patient groups (Lloyd et al, 1993). The response rates for this study are, however, at least as good as those obtained by other groups. We need to be particularly cautious in interpreting our results to mean that there is a high level of satisfaction with the service. It may be that satisfied patients are more likely to reply, but this is unlikely to differ systematically between attenders and nonattenders. Given the potential for non-response bias, it is useful to carry out a worse case scenario' analysis. So, if all non-responders were dissatisfied with the service then the actual proportion of those satisfied with their treatment would be $57 \%$ of attenders and $47 \%$ of nonattenders. We tried to increase the validity of patients' responses by assuring anonymity, but it is still possible that patients felt a need to be seen to be appreciative of the service offered and that this could have led to the reporting of high levels of satisfaction.

The most commonly reported criticism of the service was that junior medical staff change every six months. This leads to a sense of discontinuity of treatment for the patients and has particular significance in psychiatry as opposed to other specialities due to the disclosure of more personal details by the patient and the need to develop a trusting relationship with the doctor over time. A simple solution to this problem is not available given the training requirements for junior doctors. However, since $80 \%$ of respondents stated that they would like to see the consultant sometimes, perhaps a regular review by the consultant should be available to patients.

The reasons for high non-attendance rates at psychiatric clinics remain unclear. However, non-attendance is of importance in terms of the waste of scarce resources it involves and its possible clinical meaning. In a South African cohort study it has been reported that in a oneyear period, $68 \%$ of psychiatric out-patient clinic non-attenders, compared with only $20 \%$ of attenders, required readmission to hospital (Koch \& Gillis, 1991). Assertive community outreach may be a more effective model of service provision than traditional out-patient care for the severely mentally ill in the community (Muijen et al, 1992a,b; Burns et al, 1993a,b). Scarce resources need to be targeted effectively and the traditional out-patient model has potential advantages in terms of staff safety and efficient use of medical time. There is therefore a need for an evidence base upon which to formulate our response to non-attendance. This is the first study to have attempted to study this systematically and our results suggest that simple dissatisfaction may not be an important factor. There is a need now to examine how variables such as relapse, severity of psychopathology, social disorganisation, administrative failure and coherence of care may influence attendance rates.

\section{Acknowledgements}

We are extremely grateful to the reception staff in the psychiatric out-patient department for their help in the distribution and collection of questionnaires for this study, and for the cooperation of the medical staff at the Royal Free.

\section{References}

BAEKLAND, F. \& LUNDWALL, L. (1975) Dropping out of treatment: a critical review. Psychological Bulletin, 82. 738-783. 
Bishop, F. MATthews, F. J., Probert, C. S. J., et al (1991) Patients' views on how to run out-patient clinics. Journal of the Royal Society of Medicine, 84, 522-523.

BuRns, T., BEADSMOORE, A. BHAT, A. V., et al (1993a) A controlled trial of home-based acute psychiatric services. I: Clinical and social outcome. British Journal of Psychiatry. 163. 49-54.

- RAFTERY, J.. BEADSMOORE. A.. et al (1993b) A controlled trial of home-based acute psychiatric services. II: Treatment patterns and costs. British Journal of Psychiatry, 163, 55-61.

Carpenter, P. J., Morrow, G. R., Del Gaudio, A. C.. et al (1981) Who keeps the first out-patient appointment? American Journal of Psychiatry. 138, 102-105.

HUXLEY, P. J. \& WARNER. R. (1992) Case management. quality of life and satisfaction with services of long-term psychiatric patients. Hospital and Community Psychiatry. 43. 799-802.

JONES. L. \& LODGE. A. (1991) A survey of psychiatric patients views of outpatient clinic facilities. Health Bulletin. 49. 320-328.

Kaufmann. C.. Ward-Colasante. C. \& Farmer. J. (1993) Development and evaluation of drop-in centers operated by mental health consumers. Hospital and Community Psychiatry. 44. 675-678.

Косн, А. \& GiLLS, L. S. (1991) Non-attendance of psychiatric outpatients. South African Medical Journal. 80. 289-291.

LLOYD. M., BRADFORD, C. \& WEBB. S. (1993) Non-attendance at out-patient clinics: is it related to the referral process? Family Practice, 10, 111-117.

MCINTYRE. K.. FARRELl. M. \& David. A. (1989) What do psychiatric inpatients really want? British Medical Journal, 298. 156-160.
MORGAN. D. (1989) Psychiatric cases: an ethnography of the referral process. Psychological Medicine. 19. 743-753.

MuiJen. M., Marks, J. M.. ConNolly. J., et al (1992a) The daily living programme: preliminary comparison of community versus hospital based treatment for the seriously mentally ill facing emergency admission. British Journal of Psychiatry. 160. 379-384.

_. _ _ - et al (1992b) Home based care and standard hospital care for patients with severe mental illness: a randomised controlled trial. British Medical Joumal, 304. 749-754.

Rubin. H. R., Gandek. B., Rogers. W. H., et al (1993) Patients' ratings of out-patient visits in differen practice settings. Journal of the American Medical Association, 270, 835-840.

Ruggeri. M. \& Dall'Agnola. R. (1993) The development and use of the Verona Expectations for Care Scale (VECS) and the Verona Service Satisfaction Scale (VSSS) for measuring expectations and satisfaction with community-based psychiatric services in patients relatives and professionals. Psychological Medicine. 23. 511-523.

Helen Killaspy, Psychiatric Registrar; Julia Gledhill, Psychiatric Registrar, Royal Free Hospital, London and *Sube Banerjee, Senior Lecturer. Section of Epidemiology and General Practice, Institute of Psychiatry. De Crespigny Park, London SE5 8AF

*Correspondence

\title{
Mental health review tribunal medical reports
}

\author{
Khalida Ismail, Shubulade Smith and Tony Maden
}

\begin{abstract}
Aims and method Medical reports submitted to mental health review tribunals should be of a clinically acceptable standard. We examined 100 medical reports to assess whether they stated the four criteria for detention under Section 3 of the Mental Health Act 1983. We compared the standard of reports according to the seniority, qualifications and speciality of the doctor, and with the outcome from the tribunal. Results The majority of the reports were written by junior doctors and did not fulfil the criteria laid down by the Mental Health Act 1983. Consultant and forensic psychiatry status were associated with completed reports.
\end{abstract}

Clinical implications This study was performed in one hospital only but highlights the ongoing need to review and improve the workings of the Mental Health Act before reform is considered.

The introduction of the Community Care Act 1990 and subsequent inquiries into homicides by psychiatric patients, such as the Clunis Inquiry (North East and South East Thames Regional Health Authority, 1994), have led to concerns about the operation of the Mental Health Act (MHA) 1983 (Crimlisk \& Phelan, 1996). There have been calls for its reform. especially in the workings of the mental health review tribunal (MHRT) (Blom-Cooper et al, 1995. 1996). In Section 72 of the MHA 1983. 